\title{
High-pressure field assisted sintering of half-cell for all-solid-state battery
}

\author{
Alexander M. Laptev ${ }^{\mathrm{a}, *}$, Hao Zheng ${ }^{\mathrm{a}, \mathrm{b}}$, Martin Bram ${ }^{\mathrm{a}}$, Martin Finsterbusch ${ }^{\mathrm{a}}$, Olivier Guillon ${ }^{\mathrm{a}}$ \\ ${ }^{a}$ Institute of Energy and Climate Research: Materials Synthesis and Processing (IEK-1), \\ Forschungszentrum Jülich GmbH, Jülich 52425, Germany \\ ${ }^{\mathrm{b}}$ School of Materials Science and Engineering, Shanghai Jiao Tong University, \\ Shanghai 200240, PR China \\ laptev@gmx.net; mail@hao-zheng.me; m.bram@,fz-juelich.de; \\ $\underline{\text { m.finsterbusch@,fz-juelich.de; o.guillon@,fz-juelich.de }}$ \\ * Corresponding author. E-mail address: laptev@gmx.net (A. M. Laptev) \\ Declaration of interest: none
}

\begin{abstract}
High-pressure field assisted sintering (FAST/SPS) of half-cell for all-solid-state Li batteries was proposed and tested. The half-cell included the layer of lithium lanthanum zirconate (LLZO) electrolyte and the layer of mixed cathode. The mixed cathode consisted of lithium cobalt oxide (LCO) used as energy storage material and LLZO used as ionic conductor. A tool made of TZM molybdenum alloy was used to apply a high pressure of $440 \mathrm{MPa}$ during FAST/SPS at a temperature of $675^{\circ} \mathrm{C}$ ensuring stability of materials. An average relative density of sintered halfcell was around of $95 \%$. The half-cell was assembled with a lithium anode and electrochemically tested. The results were compared with the performance of a half-cell sintered in an established graphite tool at the same temperature but under a lower pressure of $50 \mathrm{MPa}$ and with a lower density (around of 78\%). The battery with half-cell sintered at high pressure showed two-fold larger surface storage capacity. Further optimization of materials and processing is in progress.
\end{abstract}


Keywords: All-solid-state battery; Mixed cathode; Field assisted sintering technique; High pressure

\section{Introduction}

All-solid-sate Li batteries (ASSLIBs) have the potential to overcome the problems of safety and stability of Li-ion batteries [1]. Current challenges of ASSLIBs are the relatively low ionic conductivity of electrolyte, insufficient compatibility of components and rapid degradation. The characteristics of ASSLIBs can be improved by enhancing the properties of single components (electrolyte, anode and cathode) and by optimization of their processing. In particular, the decrease of porosity as well as the increase of physical and chemical stability during sintering is required. The Field Assisted Sintering Technique (FAST), also known as Spark Plasma Sintering (SPS), is a promising technology for sintering of ASSLIB components individually as well as for their co-sintering [2-5]. A peculiarity of the FAST/SPS is the rapid resistance heating of tool and sintered powder (Fig. 1a). To reduce the contact resistance and to avoid sticking, a graphite foil is placed between tool elements and sintered material. The sintering kinetics is intensified by application of mechanical pressure. A standard FAST/SPS tool is made out of graphite, which allows pressures in the range of 50-75 MPa. However, in some cases, the application of larger pressures is desirable. In particular, during sintering of ASSLIB components the application of higher pressure and consequently lower temperature can eliminate or diminish the decomposition of unstable battery materials as well as their reaction with the tool. In the present paper the high pressure was enabled by the use of a FAST/SPS tool made out of TZM molybdenum alloy. The co-sintering of solid LLZO electrolyte and LCO-LLZO mixed cathode was performed under a pressure of $440 \mathrm{MPa}$ and at a temperature as low as $675^{\circ} \mathrm{C}$. The obtained half-cell was assembled with a lithium anode and electrochemically tested. The results were compared with the 
performance of a half-cell sintered at the same temperature but under a lower pressure of $50 \mathrm{MPa}$ in an established graphite tool. The battery with the half-cell sintered at high pressure showed two-fold larger surface storage capacity.

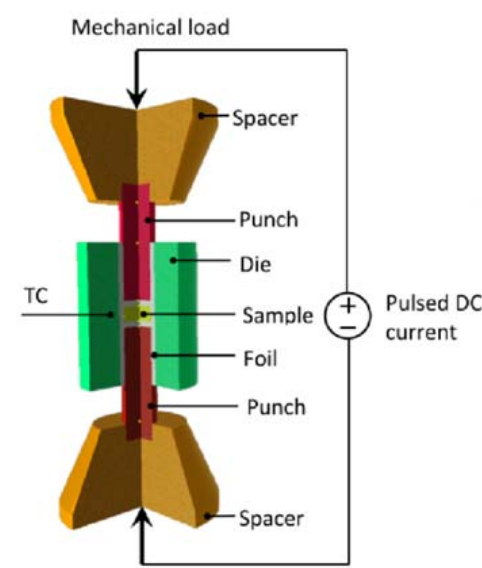

(a)
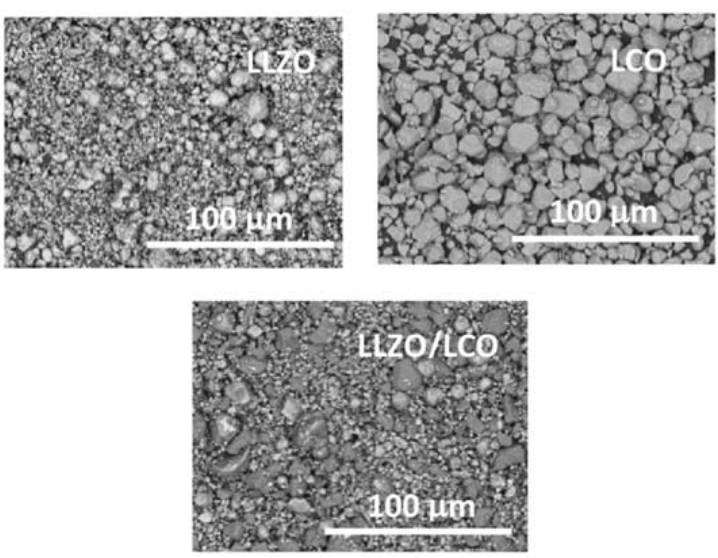

(b)

Fig. 1. (a) FAST/SPS setup with thermocouple (TC); (b) initial powders and their mixture.

\section{Materials and methods}

\subsection{Initial powders}

The electrolyte powder LLZO $\left(\mathrm{Li}_{6.54} \mathrm{Al}_{0.02} \mathrm{La}_{3} \mathrm{Zr}_{1.6} \mathrm{Ta}_{0.4} \mathrm{O}_{12}\right)$ was synthesized in-house by solid state reaction starting from $\mathrm{LiOH}$ (Merck), $\mathrm{La}_{2} \mathrm{O}_{3}$ (Merck), $\mathrm{ZrO}_{2}$ (Treibacher), $\mathrm{Ta}_{2} \mathrm{O}_{5}$ (Inframat) and $\mathrm{Al}_{2} \mathrm{O}_{3}$ (Inframat) powders. The mass of the individual components, excluding $\mathrm{LiOH}$, was applied in accordance with their molar concentration. The mass of $\mathrm{LiOH}$ was $20 \%$ higher in order to compensate the loss of lithium during processing. Mixture of LLZO and commercial LCO ( $\mathrm{LiCoO}_{2}$, MTI Corp.) powders in a 1:1 volumetric ratio was used for synthesis of mixed cathode. The morphology of initial powders and their mixture is presented in Fig. 1b. The particle size distribution was determined by laser light scattering method (Retsch, LA 950) as $\mathrm{d}_{10}=1.29 \mu \mathrm{m}, \mathrm{d}_{50}=3.28 \mu \mathrm{m}, \mathrm{d}_{90}=12.25 \mu \mathrm{m}$ for LLZO and $\mathrm{d}_{10}=6.52 \mu \mathrm{m}, \mathrm{d}_{50}=10.43 \mu \mathrm{m}$, $\mathrm{d}_{90}=15.61 \mu \mathrm{m}$ for $\mathrm{LCO}$. 


\subsection{Setting of sintering atmosphere and temperature}

To select the sintering temperature, the stability of powders and their interaction with each other and with graphite foil were studied in a TG-DTA device (Netzsch, STA 449 F1) equipped with a spectral gas analyser. Heating was carried out up to $1000^{\circ} \mathrm{C}$ at a rate of $5^{\circ} \mathrm{C} / \mathrm{min}$ in argon flow. $\mathrm{LiOH}$ powder melted at a temperature around of $468{ }^{\circ} \mathrm{C}$ and then gradually decomposed (Fig. 2a) according to reaction

$$
2 \mathrm{LiOH}=\mathrm{Li}_{2} \mathrm{O}+\mathrm{H}_{2} \mathrm{O} .
$$

This process is intensified in vacuum, which is most often used in FAST/SPS technology. Therefore, all TG-DTA and FAST/SPS experiments were carried out in argon flow. The gas analysis has shown that LLZO powder initially lost adsorbed moisture and then $\mathrm{CO}_{2}$, but remained generally stable up to $1000^{\circ} \mathrm{C}$ (Fig. 2b). In contact with graphite foil, the behavior of LLZO did not change significantly. LCO powder first released some $\mathrm{CO}_{2}$ adsorbed from atmosphere, and then remained stable up to about $900^{\circ} \mathrm{C}$ (Fig. 2c). At this temperature LCO began to decompose with release of oxygen according to reaction [6]

$$
4 \mathrm{LiCoO}_{2}=2 \mathrm{Li}_{2} \mathrm{O}+4 \mathrm{CoO}+\mathrm{O}_{2}
$$

No significant interaction of LCO with graphite foil was observed. However, Takahara et al. observed the first evidence of LCO reduction by carbon already at $600^{\circ} \mathrm{C}$ [7]. Therefore, to enhance the reducing effect the nano-sized carbon black powder (Alfa Aesar) was added to the powders and the study was repeated. In addition, the use of carbon black was intended to increase the electron conductivity of cathode. The intensive reduction of LCO by carbon black with formation of $\mathrm{CO}$ was observed by gas analysis at a temperature above of $700^{\circ} \mathrm{C}$ according to reaction

$$
2 \mathrm{LiCoO}_{2}+\mathrm{C}=\mathrm{Li}_{2} \mathrm{O}+2 \mathrm{CoO}+\mathrm{CO} .
$$


Therefore, to reliably avoid any reaction with graphite, FAST/SPS sintering was performed at $675^{\circ} \mathrm{C}$.

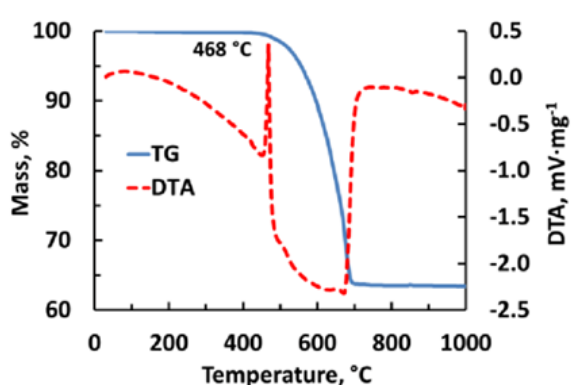

(a)

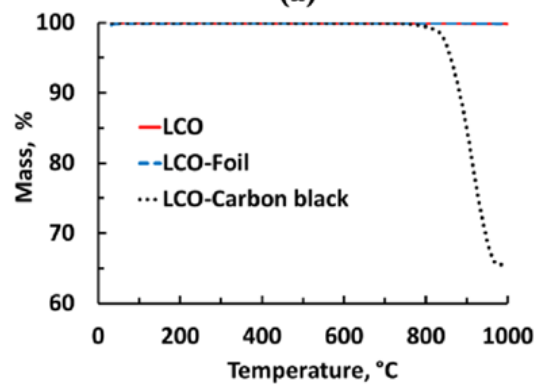

(c)

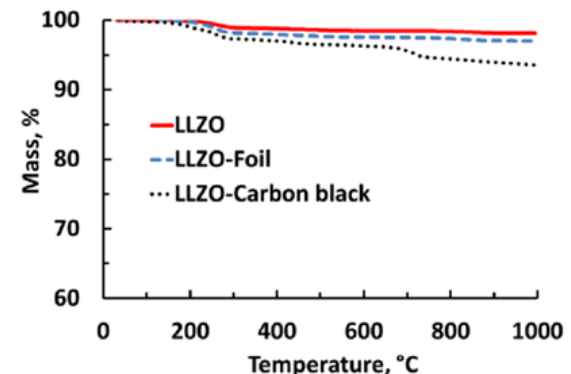

(b)

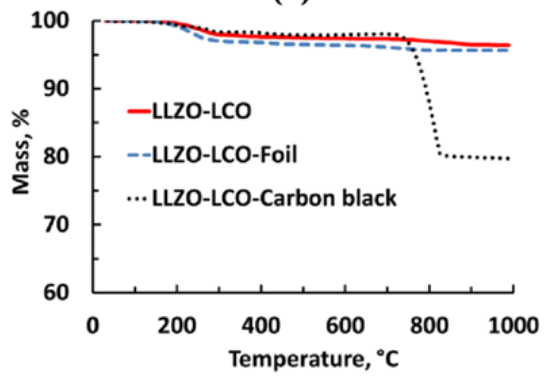

(d)

Fig. 2. TG-DTA analysis of used powders at contact with graphite foil and in mixture with carbon black: (a) LiOH, (b) LLZO, (c) LCO, (d) LLZO-LCO

\subsection{Manufacturing of half-cell and testing in battery}

A piece of the graphite foil (SGL Carbon) with a thickness of $0.35 \mathrm{~mm}$ was wrapped round and placed in the die with an internal diameter of $12 \mathrm{~mm}$ made out of TZM alloy (Plansee) fully covering the internal die wall. Then, the lower TZM punch and a disk punched from graphite foil were inserted into the die. $1 \mathrm{~g}$ of LLZO powder was poured and pre-pressed with a load of $5 \mathrm{kN}$ to flat the layer. After that, $0.5 \mathrm{~g}$ of LCO-LLZO mixture was poured and another disk was placed on top. The upper punch was inserted and the powders were pre-pressed again with a load of 50 kN. Sintering was performed in a HPD 5 facility (FCT Systeme). Argon (instead of the commonly used vacuum) was used to limit the loss of lithium. Heating to $675^{\circ} \mathrm{C}$ was carried out at a rate of $100^{\circ} \mathrm{C} / \mathrm{min}$, followed by a dwell for 10 minutes. Slow cooling at a rate of $5^{\circ} \mathrm{C} / \mathrm{min}$ 
provided crack-free samples. The temperature was controlled near the sample edge by a K-type thermocouple inserted into a radial hole in the die wall. At the beginning of heating, a pressure of $440 \mathrm{MPa}$ was applied. Before cooling, the pressure was quickly decreased to a lowest possible value of 26.5 MPa. After ejection from the die, the samples were grinded and polished resulting in a layer thickness of $1 \mathrm{~mm}$ for LLZO and $0.2 \mathrm{~mm}$ for LLZO-LCO. Both sides were spatter coated with gold. The anode in the form of a $100 \mu \mathrm{m}$ thick lithium foil was then manually attached. The obtained battery was tested in Maccor 4000 system by charging and discharging at $75^{\circ} \mathrm{C}$ with a current density of $50 \mu \mathrm{A} \cdot \mathrm{cm}^{-2}$.

\section{Results and discussion}

Two cells manufactured by high-pressure FAST/SPS are presented in Fig. 3a. The bright side is the LLZO electrolyte and the dark side is the LLZO-LCO cathode. The crack-free half-cells had a relative density of about $95 \%$. The relative density was determined from the mass, volume and with a mean theoretical density of half-cell of $5.2 \mathrm{~g} \cdot \mathrm{cm}^{-3}$, which is an average of LCO $\left(5.1 \mathrm{~g} \cdot \mathrm{cm}^{-}\right.$ $\left.{ }^{3}\right)$ and LLZO $\left(5.3 \mathrm{~g} \cdot \mathrm{cm}^{-3}\right)$ densities. The microstructure near the electrolyte/cathode interface is shown in Fig. 3b. A small amount of isolated pores is visible between single grains and on the electrolyte/cathode interface. A similar half-cell, sintered in-house in a conventional graphite tool at $675^{\circ} \mathrm{C}$ and under a pressure of $50 \mathrm{MPa}$ had a relative density of around $78 \%$. The difference in densification of mixed cathodes sintered in different tools is illustrated in Figs. 3c and $3 \mathrm{~d}$. The first charge-discharge cycle demonstrated a surface storage capacity of $0.8 \mathrm{mAh} \cdot \mathrm{cm}^{-}$ ${ }^{2}$ for battery with half-cell sintered under $440 \mathrm{MPa}$. The battery with half-cell sintered at $50 \mathrm{MPa}$ shown a twice lower surface storage capacity of $0.4 \mathrm{mAh} \cdot \mathrm{cm}^{-2}$. The achived surface storage capacity was also four-fold larger than reported in the literature for cells with similar electrolyte [8]. Further improvement of electrolyte and cathode materials and their processing is in progress. 


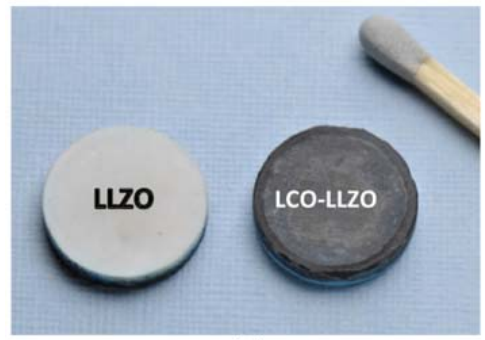

(a)

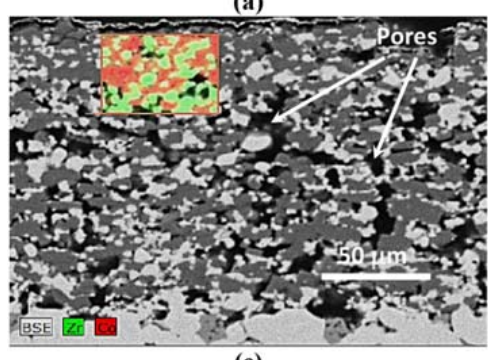

(c)

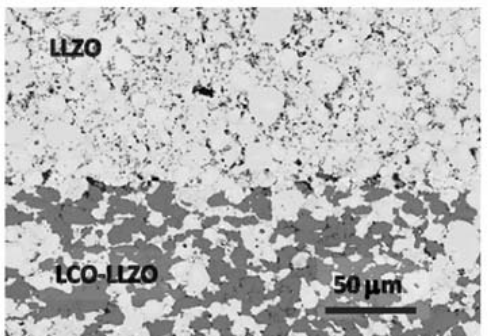

(b)

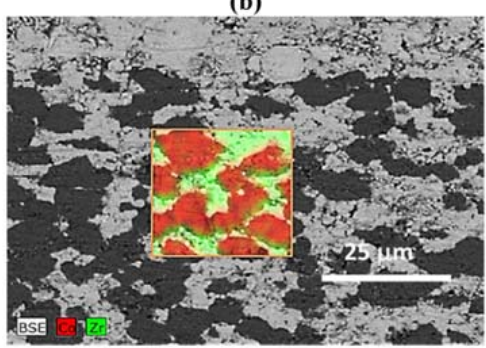

(d)

Fig. 3. (a) Half-cells manufactured using high-pressure FAST/SPS and (b) corresponding electrolyte/cathode interface. Structure of mixed cathode: (c) sintered in graphite tool at $50 \mathrm{MPa}$ and (d) sintered in TZM tool at $440 \mathrm{MPa}$.

\section{Conclusions}

High-pressure FAST/SPS with a TZM tool provides the low-temperature sintering of half-cells for all-solid-state Li batteries with high density. The sintering temperature reduced to $675^{\circ} \mathrm{C}$ was found suitable to reliably avoid the reaction between LCO, graphite foil and carbon black. The electrochemical performance of an ASSLB manufactured in high-pressure setup showed a significantly improved electrochemical performance compared to a similar battery which was sintered at the same temperature $\left(675^{\circ} \mathrm{C}\right)$ but under a moderate pressure $(50 \mathrm{MPa})$ in a conventional graphite toll. Further optimization of materials and processing is in progress.

\section{Acknowledgments}

H. Zheng acknowledges the financial support from FZJ, Germany and from OCPC, PR China through a joint post-doc program. 


\section{References}

[1] K. Kerman, A. Luntz, V. Viswanathan, Y.M. Chiang, Z. Chen, Review - Practical challenges hindering the development of solid state Li ion batteries, J. Electrochem. Soc. 164 (2017) A1731-A1744.

[2] R. Kali, A. Mukhopadhyay, Spark plasma sintered/synthesized dense and nanostructured materials for solid-state Li-ion batteries: Overview and perspective, J. Power Sources 247 (2014) 920-931.

[3] M. Botros, R. Djenadic, O. Clemens, M. Möller, H. Hahn, Field assisted sintering of finegrained $\mathrm{Li}_{7-3 \mathrm{x}} \mathrm{La}_{3} \mathrm{Zr}_{2} \mathrm{Al}_{\mathrm{x}} \mathrm{O}_{12}$ solid electrolyte and the influence of the microstructure on the electrochemical performance, J. Power Sources 309 (2016) 108-115.

[4] H. Zhu, J. Liu, Emerging applications of spark plasma sintering in all solid-state lithium-ion batteries and beyond, J. Power Sources 391 (2018) 10-25.

[5] R. Elango, A. Demortière, V. De Andrade, M. Morcrette,V. Seznec, Thick binder-free electrodes for Li-ion battery fabricated using templating approach and spark plasma sintering reveals high areal capacity, Adv. Energy Mater. 8 (2018) 1703031.

[6] E. Antolini, M. Ferretti, Synthesis and thermal stability of $\mathrm{LiCoO}_{2}$, J. Solid State Chem. 117 (1995) 1-7.

[7] H. Takahara, T. Takeuchi, M. Tabuchi, H. Kageyama, Y. Kobayashi, Y. Kurisu, S. Kondo, R. Kanno, All-solid-state lithium secondary battery using oxysulfide glass. Addition and coating of carbon to positive electrode, J. Electrochem. Soc. 151 (2004) A1539-A1544.

[8] S.W. Baek, J.M. Lee, T.Y. Kim, M.S. Song, Y. Park, Garnet related lithium ion conductor processed by spark plasma sintering for all solid state batteries, J. Power Sources 249 (2014) 197-206. 